\title{
UTILIZAÇÃO DO SORO DE LEITE BOVINO COMO REVESTIMENTO PROTETOR EM MORANGOS
}

\author{
CÁTIA MARIA DE OLIVEIRA* \\ OTNIEL FREITAS SILVA** \\ MARCIA CRISTINA DA SILVA $* * *$ \\ SUELEN ALVARENGA RÉGIS****

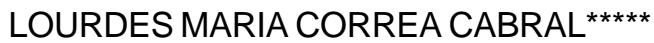 \\ SERGIOAGOSTINHO CENCI ${ }^{\star \star \star \star \star \star ~}$
}

\begin{abstract}
Este trabalho teve como objetivo aproveitar o soro de leite bovino como revestimento protetor em morangos, cultivar Dover, avaliando-se aspectos biológicos e sensoriais dos frutos durante o armazenamento a $10^{\circ} \mathrm{C}$ e $20^{\circ} \mathrm{C}$. Os morangos foram pré-selecionados, lavados em água corrente, sanificados com cloro e secos. Utilizaram-se 10 caixas de morangos para cada tratamento contendo oito frutos cada. A aplicação do soro ocorreu pela imersão dos frutos em recipiente contendo soro a $100 \%, 50 \%$ e $0 \%$ (controle). A perda de peso nos frutos armazenados a $20^{\circ} \mathrm{C}$ e tratados com soro a $50 \%$ e $100 \%$ foi de $1,2 \%$ e $1,3 \%$, respectivamente, tendo o controle apresentado perda de $2,5 \%$. Nos frutos armazenados a $10^{\circ} \mathrm{C}$, a perda de peso foi de $1,8 \%$ nos frutos tratados com soro a $50 \%$ e $100 \%$ e de $3,2 \%$ para o controle. A menor contaminação por bolores e leveduras ocorreu no tratamento com soro $100 \% / 10^{\circ} \mathrm{C}$. O soro conferiu aspecto brilhante aos frutos, menor ressecamento e sépalas mais verdes, especialmente no tratamento a 100\%. Concluiu-se que a aplicação do soro diminuiu a incidência de fungos e preservou características importantes dos frutos, mantendo seu aspecto visual original.
\end{abstract}

PALAVRAS-CHAVE: MORANGO (Fragaria spp.); SORO DE LEITE BOVINO; REVESTIMENTO COMESTÍVEL.

* Mestre em Ciência de Alimentos, Centro Federal de Educação Tecnológica de Química de Nilópolis, Unidade Rio de Janeiro, RJ (e-mail: catiasaqn@yahoo.com.br).

** Mestre em Agronomia, Embrapa Agroindústria de Alimentos, Rio de Janeiro, RJ (e-mail: otofreitas@gmail.com).

*** Mestre em Ciência de Alimentos, Centro Federal de Educação Tecnológica de Química de Nilópolis, Unidade Rio de Janeiro, RJ (e-mail: marciacsilv@gmail.com).

*** Graduanda em Economia Doméstica, Universidade Federal Rural do Rio de Janeiro, Rio de Janeiro, RJ (e-mail: suelenar@gmail.com).

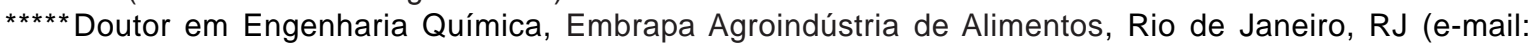
cabral@ctaa.embrapa.br).

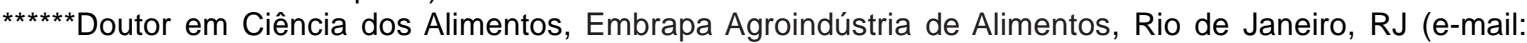
cenci@ctaa.embrapa.br). 


\section{INTRODUÇÃO}

O consumo de morangos ocorre desde épocas remotas, havendo relatos da cultura do morangueiro das espécies Fragaria vesca e Fragaria moschata já no século XV na França e na Inglaterra (SANHUEZA et al., 2005).

Os morangos são frutos muito perecíveis, e por isso podem ocorrer grandes perdas caso não sejam utilizadas técnicas corretas de colheita e pós-colheita. Tais perdas podem assumir caráter quantitativo e/ou qualitativo, o que implica em prejuízos para o produtor, o comerciante e o consumidor. Seus tecidos, macios e facilmente danificáveis, estão sujeitos a invasões por organismos que causam apodrecimento dos frutos e seu manuseio exige extremos cuidados (GALEGÁRIO et al., 2005).

O soro de leite é o líquido que escorre da coalhada durante a precipitação da caseína do leite, e segundo SGARBIERI (2004) pode ser obtido em laboratório ou na indústria por três processos distintos: a) coagulação enzimática (enzima quimosina), resultando no coágulo de caseínas, matériaprima para a produção de queijos e soro "doce"; b) precipitação ácida no $\mathrm{pH}$ isoelétrico (pl), resultando na caseína isoelétrica que é transformada em caseinatos e em soro ácido; e c) separação física das micelas de caseína por microfiltração, obtendo-se concentrado de micelas e as proteínas do soro na forma de concentrado ou isolado protéico.

A separação das caseínas do leite origina as proteínas do soro, definidas como as proteínas que permanecem solúveis após a coagulação das caseínas em $\mathrm{pH} 4,6$ a $20^{\circ} \mathrm{C}$. As proteínas do soro somam aproximadamente $20 \%$ das proteínas totais do leite, sendo $80 \%$ delas representadas pelas caseínas (ANTUNES, 2003).

As principais proteínas presentes no soro são a $\alpha$-lactoalbumina, $\beta$-lactoglobulina, imunoglobulina, albumina sérica bovina e glicomacropeptídeo. Presentes em menor quantidade, mas comercialmente importantes estão a lactoferrina e a lactoperoxidase (DOULTANI, TURHAN e ETZEL, 2004).

As proteínas do soro apresentam características físico-químicas que resultam em importantes propriedades funcionais para aplicações alimentares, tais como boa solubilidade em água, capacidade de transportar pequenas moléculas lipofílicas ( $\beta$-lactoglobulina) e íons (lactoferrina), ação tensoativa que permite a obtenção e estabilização de sistemas bifásicos (emulsões e espuma), propriedades gelificantes, que possibilitam a retenção de grandes quantidades de água e outras pequenas moléculas dentro da matriz, conferindo estabilidade aos alimentos (TORRES, 2005). SGARBIERI (2004) relatou várias atividades dessas proteínas como: imunomoduladora (imunoglobulinas); antimicrobiana (lactoferrina; lactoperoxidase; $\alpha$-lactalbumina e imunoglobulinas); antiviral (lactoferricina); anticancerígena (concentrado de proteínas do soro; lactoferrina; $\beta$-lactoglobulina); antiúlcera (concentrado de proteínas do soro; $\alpha$-lactalbumina) e proteção ao sistema cardiovascular.

Tradicionalmente, o soro foi visto como resíduo sem qualquer valor comercial e descarregado em cursos de água ou incorporado em rações para animais. Essa abordagem foi abandonada, devido às excelentes propriedades nutricionais e funcionais do soro. Com isso, o soro de leite passou a ser tratado como produto com elevado valor agregado (TORRES, 2005).

A principal fonte geradora do soro de leite é a fabricação de queijos. O descarte do soro sem tratamento eficiente não constitui apenas crime previsto por lei, representando o desperdício de alimento de excelente qualidade e composição que permite diversas aplicações nas indústrias de alimentos e farmacêutica (FLORENTINO et al., 2005).

A busca por conservantes naturais para alimentos aumentou e o soro de leite, resíduo produzido em grande volume, apresenta baixo custo e potencial para aplicação em alimentos. Neste contexto, o objetivo deste trabalho foi utilizar o soro doce de leite bovino como revestimento protetor na pós-colheita de morangos, avaliando-se parâmetros de qualidade ao longo do período de armazenamento. 


\section{MATERIAL E MÉTODOS}

\subsection{OBTENÇÃO DO SORO DE LEITE BOVINO}

O soro de leite bovino foi obtido numa indústria de laticínios, situada no estado de Minas Gerais, sendo oriundo da fabricação de queijo minas frescal pelo processo de coagulação enzimática (quimosina) e desse modo chamado de soro "doce". O soro foi armazenado em câmara fria a $4^{\circ} \mathrm{C}$ até a sua utilização.

O soro a ser aplicado no morango foi processado em sistema de microfiltração, utilizando-se membranas tubulares de polissulfona com poro de $0,3 \mu \mathrm{m}$, visando reter bolores e leveduras por ventura presentes. Alimentou-se o sistema de microfiltração com 4 litros de soro bruto, sendo obtido ao final do processo 1 litro de soro microfiltrado (permeado).

\subsection{RECEPÇÃO E PREPARO DOS FRUTOS}

Morangos (Fragaria spp.), cultivar Dover, provenientes de cultivo comercial em Barbacena (MG) foram colhidos com 3/4 de coloração avermelhada. Os morangos foram pré-selecionados para garantir homogeneidade com relação ao tamanho e estágio de maturação e ainda evitar a utilização de frutos lesionados ou contaminados. Os frutos foram lavados em água corrente, sanificados com cloro (200 ppm e 8\% de cloro ativo) por 15 minutos e secos em temperatura ambiente sobre compressas de tecido de algodão, previamente autoclavadas. Das 30 caixas de morangos obtidas (8 frutos por caixa) foram utilizadas 10 caixas por tratamento.

\subsection{APLICAÇÃO DO SORO DE LEITE BOVINO NOS FRUTOS}

Verificou-se o volume do soro de leite bovino (1 litro) em proveta de vidro, sendo $500 \mathrm{~mL}$ diluídos com água destilada para a concentração de $50 \%$ (denominado de soro a $50 \%$ ). O soro de leite restante $(500 \mathrm{~mL})$ foi mantido dessa forma para aplicação nos frutos, sendo denominado de soro a $100 \%$.

Os soros $50 \%$ e $100 \%$ foram acondicionados em recipientes plásticos, previamente esterilizados (aplicação de raios ultra-violeta durante 20 minutos) e identificados de acordo com a concentração de soro recebida. O soro (50\% e 100\%) no momento da aplicação estava na temperatura de $4^{\circ} \mathrm{C}$.

A aplicação ocorreu pela imersão dos frutos durante 3 minutos em recipiente contendo soro a $100 \%, 50 \%$ e o controle (0\% de soro), logo após a recepção e preparo dos frutos. Em seguida, as amostras foram embaladas e armazenadas em câmara germinativa.

\subsection{ARMAZENAMENTO DOS FRUTOS}

Cada tratamento (soro 50\%; soro $100 \%$; controle) foi composto por dez caixas de morango contendo cada caixa oito frutos, sendo cinco caixas armazenadas em câmara germinativa (BOD) a $20^{\circ} \mathrm{C}$ e cinco a $10^{\circ} \mathrm{C}$.

\subsection{DETERMINAÇÕES ANALÍTICAS}

\subsubsection{Soro de leite}

A determinação do pH do soro foi realizada após a filtração, utilizando-se pHmetro digital (Beckman - Zeromatec SS-3), conforme metodologia descrita por METROHM ION ANALYSIS (2008). 
Avaliou-se a concentração de proteínas pelo método de LOWRY et al. (1951). Determinou-se o perfil protéico mediante análises eletroforéticas do material protéico, utilizando o sistema descontínuo de tampões e concentrações descrito por LAEMMLI (1970). A atividade da lactoperoxidase foi determinada pelo teste de oxidação do pirogalol, conforme descrito pela SIGMA (1994). De acordo com GOTHEFORS e MARKLUND (1975), esse teste pode ser aplicado para mensurar a atividade da lactoperoxidase presente em leite humano e na saliva de bebês recém-nascidos.

\subsubsection{Morangos}

Os sólidos solúveis totais ( ${ }^{\circ} \mathrm{Brix}$ ) foram determinados por refratometria, utilizando-se refratômetro digital (Atago PR 101). Os frutos foram avaliados quanto a perda de peso em balança semi-analítica, considerando-se a diferença entre o peso da embalagem contendo os frutos no tempo zero (logo após a aplicação do soro) e o peso medido no $4^{\circ} ; 6^{\circ}$ e $10^{\circ}$ dia de armazenamento. Verificou-se a incidência de bolores e leveduras por inspeção visual dos morangos armazenados, avaliando-se a presença de Unidades Formadoras de Colônias (UFC) visíveis, seguida de anotações dos dados obtidos para posterior análise. Mesmo após a automação da maior parte dos setores industriais, a inspeção de frutas continua sendo melhor realizada por humanos (SIMÕES e COSTA, 2003). O aspecto visual foi avaliado durante o armazenamento, observando-se o brilho dos frutos, grau de ressecamento e o aspecto do pedicelo e das sépalas.

Efetuou-se análise estatística para avaliação da significância da perda de peso entre os grupos de amostras de morango, submetidos aos diferentes tratamentos, empregando o teste t (CALLEGARIJACQUES, 2004) ao nível de significância de $5 \%(P<0,05)$.

\section{RESULTADOS E DISCUSSÃO}

\subsection{SORO DE LEITE BOVINO}

A concentração de proteínas foi de 9,0 mg/mL e 3,8 mg/mL, antes e depois da microfiltração, respectivamente. A retenção de agregados residuais de caseína presentes no soro de leite, ou ainda a adsorção na membrana podem justificar a diferença na concentração protéica do soro antes e após a microfiltração.

A análise do soro antes e após a microfiltração pela técnica de SDS-PAGE não mostrou diferença entre o perfil de bandeamento protéico das amostras. Após o descoramento do gel foram visualizadas três bandas protéicas principais nas amostras de soro microfiltrado e não-microfiltrado. Essas bandas apresentaram os seguintes valores de massa molar aparente: 56,99 kDa; 18,17 kDa e $15,85 \mathrm{kDa}$ (Figura 1).

Dentre as proteínas mais abundantes, presentes no soro com massas molares próximas das encontradas, destacaram-se a imunoglobulina ( $55 \mathrm{kDa}$ ); a $\beta$-lactoglobulina (18 kDa), e a $\alpha$-lactalbumina (14 kDa), indicando a possível identidade das proteínas reveladas pela coloração com Coomassie blue. As proteínas presentes em menor quantidade no soro do leite não são visíveis no gel. Para a visualização dessas proteínas seria necessária a concentração da amostra antes da análise por eletroforese ou a utilização de técnica de coloração mais sensível como, por exemplo, a coloração pela prata.

BORGES et al. (2001) analisaram concentrados protéicos de soro pela técnica de SDS-PAGE e identificaram bandas protéicas referentes a BSA e a $\alpha$-lactalbumina e especularam que a banda com massa molar de $18,4 \mathrm{Kda}$ seria a $\beta$-lactoglobulina. A atividade da peroxidase presente no soro de leite foi de $0,1 \mathrm{U} / \mathrm{mL}$ de lactoperoxidase. 


\section{FIGURA 1 - COMPARAÇÃO DOS PERFIS PROTÉICOS POR SDS-PAGE DO SORO ANTES DE SER MICROFILTRADO EM MEMBRANA DE 0,3 $\mu \mathrm{m}$ (2) E APÓS A MICROFILTRAÇÃO EM MEMBRANA DE 0,3 $\mu \mathrm{m}$ (3)}

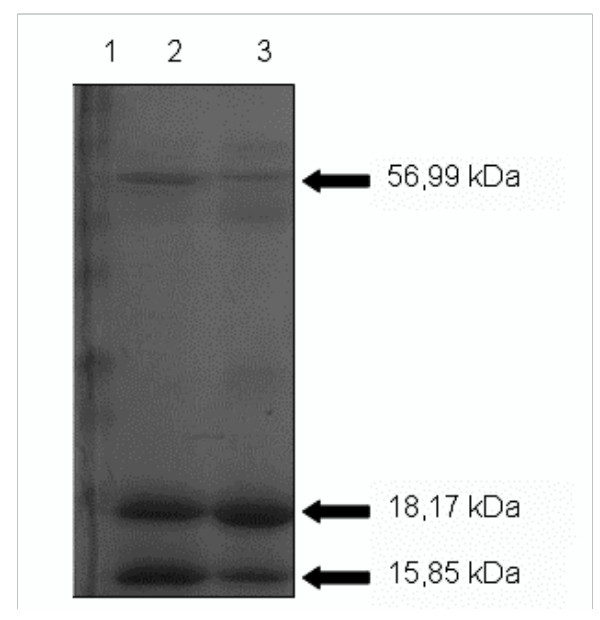

Em (1) padrões de massa molecular utilizados. As setas indicam as massas moleculares encontradas.

\subsection{FRUTOS}

Os frutos armazenados a $20^{\circ} \mathrm{C}$ apresentaram perda de peso de $1,2 \%$ e $1,3 \%$ para os tratamentos com 50\% e 100\% de soro, respectivamente. Já nos frutos não-tratados com soro de leite (controle) a perda de peso foi de $2,5 \%$. Os frutos armazenados a $10^{\circ} \mathrm{C}$ mostraram perda de peso de $1,8 \% \mathrm{em}$ ambos tratamentos (50\% e 100\% de soro) e de 3,2\% para os frutos controle (Figura 2). A análise estatística (teste t) demonstrou diferença significativa $(P<0,05)$ da perda de peso do grupo controle em relação aos grupos com aplicação de 50 e 100\% do soro de leite, tanto para as amostras armazenadas $\mathrm{a} 10^{\circ} \mathrm{C}$ quanto para aquelas armazenadas a $20^{\circ} \mathrm{C}$.

\section{FIGURA 2 - PERDA DE PESO EM MORANGOS REVESTIDOS COM SORO DE LEITE NAS CONCENTRAÇÕES DE 0\%; 50\% E 100\% ARMAZENADOS A $10^{\circ} \mathrm{C} / 10$ DIAS}

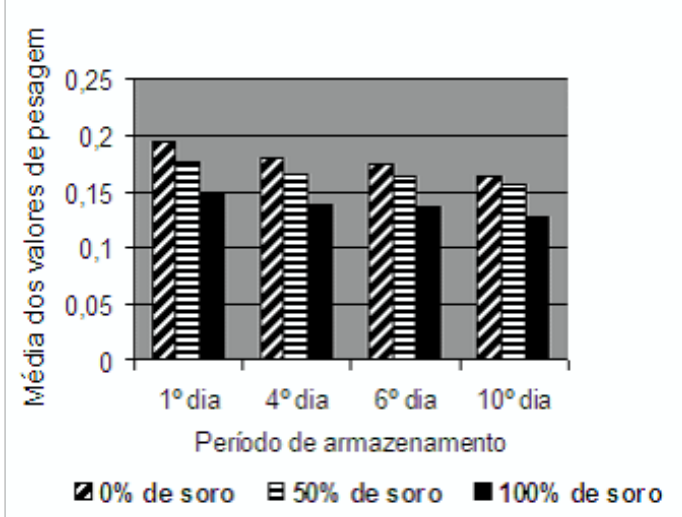


A aplicação do soro, especialmente na concentração de 100\%, promoveu melhora no aspecto visual dos frutos conferindo aspecto brilhante e menor ressecamento. O pedicelo e as sépalas estavam mais verdes. MARTINS et al. (2006) empregaram a inspeção visual para a quantificação de danos póscolheita em pêssegos, tendo constatado alta incidência dos danos mecânicos. Apesar desses dados não estarem diretamente correlacionados com o presente trabalho, a comparação é viável para enfatizar a importância da análise visual.

A utilização de películas comestíveis tem sido bastante explorada para revestimento de frutas e hortaliças frescas, visando minimizar a perda de umidade e reduzir as taxas de respiração, além de conferir aparência brilhante e atraente aos produtos (BALDWIN et al., 1999; HENRIQUE e CEREDA, 1999; DIAB et al., 2001; JIANG e LI, 2001). O brilho e melhor integridade estrutural conferidos pelas películas comestíveis tornam os produtos mais atraentes para o consumidor (KESTER e FENNEMA, 1986; HERSHKO e NUSSINOVITCH, 1998; NUSSINOVITCH, 1998; BALDWIN et al., 1999).

Verificou-se valor médio de 7,6 e 8,4 para sólidos solúveis totais (SST), respectivamente no $1^{\circ} \mathrm{e}$ no $10^{\circ}$ dia de armazenamento das amostras controle. Para os frutos tratados com $50 \%$ e $100 \%$ de soro, esse valor foi de 7,3 no $10^{\circ}$ dia. Os valores obtidos na análise de SST podem estar relacionados com a perda de água do material. Os sólidos solúveis tendem a se concentrar com a perda de água, elevando os resultados de SST. Possivelmente, o tratamento com soro reduziu a perda de água dos frutos, visto que o valor de SST foi menor nos dois tipos de tratamento com soro quando comparados ao controle.

O crescimento de bolores e leveduras foi considerável em todos os frutos armazenados a $20^{\circ} \mathrm{C}$, o que impossibilitou seu armazenamento por período superior a quatro dias. Já nos frutos armazenados $a 10^{\circ} \mathrm{C}$ houve maior contaminação no grupo controle e no tratamento com $50 \%$ de soro (Tabela 1).

MARTIN-DIANA et al. (2006) utilizaram permeado de soro em diferentes concentrações como agente sanitizante natural para lavagem de alface e cenoura. Observaram que o permeado de soro, especialmente na concentração de 3\%, promoveu eficiente redução na carga microbiana desses produtos quando comparado ao cloro 120 ppm.

\section{TABELA 1 - AVALIAÇÃO DA CONTAMINAÇÃO POR BOLORES E LEVEDURAS EM MORANGOS TRATADOS COM 0\%; 50\% E 100\% DE SORO DE LEITE ARMAZENADOS A $10^{\circ} \mathrm{C}$}

\begin{tabular}{l|cccc}
\hline \multirow{2}{*}{ Tratamentos } & \multicolumn{5}{c}{$N^{\circ}$ de caixa (s) de morangos contaminada (s) } \\
\hline & $1^{\circ}$ dia & $4^{\circ}$ dia & $6^{\circ}$ dia & $10^{\circ}$ dia \\
\hline 0\% de soro & 0 & 0 & 3 & 4 \\
$50 \%$ de soro & 0 & 0 & 3 & 4 \\
$100 \%$ de soro & 0 & 0 & 0 & 1 \\
\hline
\end{tabular}

O efeito antimicrobiano do soro de leite bovino, segundo MARTIN-DIANA et al. (2006), está relacionado com seu baixo $\mathrm{pH}$ devido a presença do ácido lático que consegue penetrar na célula do microrganismo na forma dissociada e provocar sua morte. Além disso, o soro contém bacteriocinas termorresistente e outros peptídeos bioativos (caseinomacropeptídeos).

A hidrólise da k-caseína do leite pela quimosina, durante a fabricação de queijo, promove 
a liberação de peptídio terminal de 64 aminoácidos chamado de glicomacropeptídeo. Esse peptídio, que não existe no soro ácido, confere proteção contra toxinas, bactérias e vírus (BRODY, 2000).

Durante muito tempo atribuiu-se à lactoferrina, proteína que compõe o soro de leite bovino, apenas a capacidade de seqüestrar o ferro (nutriente essencial), tornando-o indisponível para patógenos. Depois descobriu-se que a ação bactericida dessa proteína decorre da sua interação direta com a bactéria (FARNAUD e EVANS, 2003). De acordo com DIONYSIUS e MILNE (1997), sua atividade bactericida está associada com peptídeos catiônicos específicos presentes na região $\mathrm{N}$-terminal da lactoferrina.

A lactoperoxidase é uma porfirina contendo peroxidase secretada pela glândula mamária. Essa enzima é parte de um complexo que ultimamente tem sido relacionado com efeitos antimicrobianos. A lactoperoxidase catalisa a oxidação do tiocianato ( $(\mathrm{SCN})$ ) para hipotiocianato em presença do peróxido de hidrogênio produzido por bactérias endógenas (AIMUTIS, 2004). A lactoperoxidase forma com o tiocianato e o peróxido de hidrogênio, ambos normalmente presentes no leite, o sistema lactoperoxidase (sistema LPS) que é capaz de inibir o crescimento e/ou causar a morte de microrganismos devido a alterações celulares (WOLFSON e SUMNER, 1993). Esse sistema antimicrobiano, que ocorre naturalmente no leite e na saliva, é usado em alimentos, cosméticos e aplicações clínicas por ser seguro (GRAS - geralmente reconhecido como seguro) e abranje amplo espectro de ação (TOUCH et al., 2004).

Quando testado in vitro o sistema LPS promoveu a inibição do crescimento e da proliferação de vários patógenos, incluindo espécies de bactérias e fungos (JACOB et al.,2000). Já quando testado in vivo, o sistema LPS exerceu efeito bio-preservativo prevenindo o crescimento e a sobrevivência de S. enteritidis em frutas e vegetais minimamente processados (TOUCH et al. 2004).

Filme fino preparado com materiais biológicos (como polissacarídios, proteínas, lipídios e derivados), o biofilme age como barreira a elementos externos e, conseqüentemente, pode proteger o produto e aumentar a sua vida-de-prateleira. Algumas possíveis propriedades funcionais dos filmes incluem: retardar a migração de umidade, o transporte de gases $\left(\mathrm{O}_{2}, \mathrm{CO}_{2}\right)$, a migração de óleo ou gordura, o transporte de solutos, oferecer integridade estrutural adicional aos alimentos, podendo também reter compostos aromáticos e carregar aditivos alimentícios ou componentes com atividade anti-bacteriana ou anti-fúngica, mediante liberação controlada sobre o produto em que foi aplicado (TANADA-PALMU, FAKHOURI e GROSSO, 2002).

Os filmes e coberturas comestíveis são vistos como alternativa para aumentar a vida-de-prateleira de frutas e vegetais, protegendo-os dos efeitos da umidade e do oxigênio e retardando, assim, a sua deterioração (FAKHOURI, BATISTA e GROSSO, 2003).

A aplicação de concentrado protéico de soro de leite bovino em ovos com casca ocasionou a redução da perda de peso e manteve a qualidade interna dos ovos, quando comparados aos que não receberam esse tipo de cobertura e que foram armazenados em condições semelhantes (ALLEONI e ANTUNES, 2004).

\section{CONCLUSÃO}

O soro de leite bovino constitui subproduto promissor para utilização na indústria de alimentos em diversos segmentos, merecendo estudos adicionais para esclarecer melhor suas propriedades.

A aplicação do soro de leite como revestimento comestível em morangos, especialmente na concentração de $100 \%$, reduz a incidência de bolores e leveduras quando combinada com armazenamento a $10^{\circ} \mathrm{C}$. Também reduz a perda de peso dos frutos, preserva características importantes e mantém seu aspecto visual original, resultando em maior aceitação pelos consumidores. 


\begin{abstract}
BOVINE MILK WHEY UTILIZATION AS PROTECTIVE COVERING IN STRAWBERRIES

The objective of this study was the use of the bovine sweet milk whey as protective covering in strawberries "cultivar Dover" evaluating sensorial and microbiological aspects of the fruits during storage at $10^{\circ} \mathrm{C}$ and $20^{\circ} \mathrm{C}$. Strawberries were pre-selected, washed in abundant potable water, hygienized with chlorine and dried. Ten boxes containing eight samples each were used for each treatment. Application of the whey occurred by the immersion in recipients containing $100 \%, 50 \%$ and $0 \%$ (control). The weight loss in fruits stored at $20^{\circ} \mathrm{C}$ and treated with whey at $50 \%$ and $100 \%$ was of $1.2 \%$ and $1.3 \%$, respectively, and the control showed a loss of $2.5 \%$. In fruits stored at $10^{\circ} \mathrm{C}$, the weight loss was $1.8 \%$ for milk whey $50 \%$ and $100 \%$ and $3.2 \%$, for the control sample. The smaller contamination of moulds and yeasts occurred with milk whey $100 \% / 10^{\circ} \mathrm{C}$ treatment. The whey conferred a more brilliant aspect to the fruits, less dried up, and sepals with prominent green colour, especially in $100 \%$ whey milk treatment. In conclusion, the use of a $100 \%$ bovine sweet milk whey solution in strawberries stored at $10^{\circ} \mathrm{C}$ can minimize moulds and yeasts contamination and preserves important characteristics, maintaining its original visual aspect.
\end{abstract}

KEY-WORDS: STRAWBERRY (Fragaria spp.); BOVINE SWEET MILK WHEY; EDIBLE COATING.

\title{
REFERÊNCIAS
}

1 AIMUTIS, W. R. Bioactive properties of milk proteins with particular focus on anticariogenesis. Journal of Nutrition, v.134, p. 989S-995S, 2004.

2 ALLEONI, A. C. C.; ANTUNES, A. J. Internal quality of eggs coated with whey protein concentrate. Scientia Agrícola, Piracicaba, v. 61, n. 3, p. 276-280, 2004.

3 ANTUNES, A. J. Funcionalidade de proteínas do soro de leite bovino. Barueri: Manole, 2003. 150 p.

4 BALDWIN, E. A.; BURNS, J. K.; KAZOKAS, W.; BRECHT, J. K.; HAGENMAIER, R. D.; BENDER, R. J.; PESIS, E. Effect of two edible coatings with different permeability characteristics on mango (Mangifera indica L.) ripening during storage. Postharvest Biology and Technology, v. 17, n. 3, p. 215-226, 1999.

5 BORGES, P. F. Z.; SGARBIERI, V. C.; DIAS, N. F. G. P.; JACOBUCCI, H. B.; PACHECO, M. T. B.; BALDINI, V. L. S. Produção piloto de concentração de proteínas de leite bovino: composição e valor nutritivo. Brazilian Journal of Food Technology, v. 4, p. 1-8, 2001.

6 BRODY, E. P. Biological activities of bovine glycomacropeptide. British Journal of Nutrition, v. 84, p. S39S46, 2000.

7 CALLEGARI-JACQUES, S.M. Bioestatística: princípios e aplicações. Porto Alegre: Armed, 2004. 255 p.

8 DIAB, T.; BILIADERIS, C. G.; GERASOPOULOS, D.; SFAKIOTAKIS, E. Physicochemical properties and application of pullulan edible films and coatings in fruit preservation. Journal of the Science of Food and Agriculture, v. 81, n. 10, p. 988-1000, 2001.

9 DOULTANI, S.; TURHAN, N.; ETZEL, M. Fractionation of proteins from whey using cation exchange chromatography. Process Biochemistry, v. 39, p. 1737-1743, 2004.

10 DIONYSIUS, D. A.; MILNE, J. M. Antibacterial peptides of bovine lactoferrin: purification and characterization. Journal Dairy Science, v. 80, p. 667-674, 1997.

11 FAKHOURI, F. M.; BATISTA, J.; GROSSO, C. Efeito de coberturas comestíveis aplicadas em goiabas in natura (Psidium guajava) I. desenvolvimento e caracterização de filmes comestíveis de gelatina, triacetina e ácidos graxos. Brazilian Journal Food Technology, v.6, n.2, p. 301-308, 2003.

12 FARNAUD, S.; EVANS, R. W. Review - lactoferrin- a multifunctional protein with antimicrobial properties. Molecular Immunology, v. 40, p. 395-405, 2003.

13 FLORENTINO, E. R. Caracterização do soro de queijo visando processo de aproveitamento. Higiene Alimentar, v. 19, n. 130, p. 30-32, 2005. 
14 GALEGÁRIO, F. F.; AMARO, M.; WEIHMANN, C. R.; SANHUEZA, R. M. V.; FREIRE, J. de M.; DO AMARANTE, C. V. T. Sistema de produção de morango para mesa na região da serra gaúcha e encosta superior do nordeste. [2005]. Disponível em: <http://sistemasdeprodução.cnptia.embrapa.br/FontesHTML/ Morango/MesaSerraGaucha/colheita.htm>. Acesso em: 10 setembro 2006.

15 GOTHEFORS, L.; MARKLUND, S. Lactoperoxidase activity in human milk and saliva of newborn infants. Infection and Immunity, v.11, n. 6, p. 1210-1215, 1975.

16 HENRIQUE, C. M.; CEREDA, M. P. Utilização de biofilmes na conservação pós-colheita de morango (Fragaria Ananassa Duch). Revista Ciência e Tecnologia de Alimentos, v. 19, n. 2, p. 231-240, 1999.

17 HERSHKO, V.; NUSSINOVITCH, A. Physical properties of alginate-coated onion (Allium cepa) skin. Food Hydrocolloids, v. 12, n. 2, p. 195-202, 1998.

18 JACOB, B. M.; ANTONY, E. K.; SREEKUMAR, B.; HARIDAS, M. Thiocyanate mediated antifungal and antibacterial property of goat milk lactoperoxidase. Life Sciences, v. 66, n. 25, p. 2433-2439, 2000.

19 JIANG, Y.; LI, Y. Effects of chitosan coating on postharvest life and quality of longan fruit. Food Chemistry, v. 73, n. 2 , p. 139-143, 2001.

20 LAEMMLI, U. K. Cleavage of structural proteins during the assembly of the head of bacteriophage T4. Nature, v. 227, p. 680-685, 1970.

21 LOWRY, O. H.; ROSEBROUGHT, N. J.; FARR, A. L.; RANDALL, R. J. Protein measurement with the Folin phenol reagent. [1951]. Disponível em: <www.jbc.org>. Acesso em: 23 Outubro 2006.

22 KESTER, J. J.; FENNEMA, O. R. Edible films and coatings: a review. Food Technology, v. 40, n. 12, p. 4759, 1986.

23 MARTIN-DIANA, A. B.; RICO, D.; FRIAS, J.; MULCAHY, J.; HENEHAN, G. T. M.; BARRY-RYAN, C. Whey permeate as a bio-preservative for shelf life maintenance of fresh-cut vegetables. Innovative Food Science \& Emerging Technologies, v. 7, p. 112-123, 2006.

24 MARTINS, M. C.; LOURENÇO, S. A.; GUTIERREZ, A. S. D.; JACOMINO, A. P.; AMORIM, L. Quantificação de danos pós-colheita em pêssegos no mercado atacadista de São Paulo. Fitopatologia Brasileira v. 31, n. 1 , p. $5-10,2006$

25 METROHM ION ANALYSIS. Titrino 794 basic titrino: instructions for use. Switzerland, 2008. 194 p. (Metrohm program version 5.794.0010).

26 NUSSINOVITCH, A. Hydrocolloid coating of foods: a review. Leatherhead Food Industry Journal, v. 1, n. 3, p. 174-188, 1998.

27 SANHUEZA, R. M. V.; HOFFMANN, A.; ANTUNES, L.E.C.; FREIRE, J. de M. Sistema de produção de morango para mesa na região da serra gaúcha e encosta superior do nordeste. [2005]. Disponível em: < http://sistemasdeprodução.cnptia.embrapa.br/FontesHTML/Morango/MesaSeraGaucha/ index.htm>. Acesso em: 10 setembro 2006.

28 SGARBIERI, V. C. Propriedades fisiológicas-funcionais das proteínas do soro de leite. Revista de Nutrição de Campinas, São Paulo, v. 17, n. 4, p. 397-409, out./dez. 2004.

29 SIGMA on line. Enzymatic assay of peroxidase (EC 1. 11.1 7) [1994]. Disponível em: http://www.sigmaaldrich.com/ img/assets/18160/Peroxidase.pdf. Acesso em: 20 junho 2005.

30 SIMÕES, A. S.; COSTA, A. H. R. Classificação de laranjas baseada em padrões visuais [2003]. Disponível em: <http://www.sorocaba.unesp.br/professor/assimoes/publicacoes/sbai2003.pdf>. Acesso em: 23 outubro 2007.

31 TANADA-PALMU, P.; FAKHOURI, F.M.; GROSSO, C.R.F. Filmes biodegradávei: extensão da vida útil de frutas tropicais. Revista Biotecnologia, Ciência \& Desenvolvimento, n. 26, p. 12-17; 2002.

32 TORRES, D. P. M. Gelificação térmica de hidrolisados enzimáticos de proteínas do soro de leite bovino - comportamento de sistemas aquosos mistos péptidos-polissacarídeos. Braga, 2005. $100 \mathrm{f}$. Tese (Mestrado em Biotecnologia/Engenharia de Bioprocessos), Departamento de Engenharia Biotecnológica, Universidade do Minho. 
33 TOUCH, V.; HAYAKAWA, S.; YAMADA, S.; KANEKO, S. Effects of a Lactoperoxidase-thiocyanate-hygrogen peroxide system on Salmonella enteritidis in animal or vegetable foods. International Journal of Food Microbiology, v. 93, n. 2, p. 175-183, jun. 2004.

34 WOLFSON, L. M.; SUMNER, S.S. Antibacterial activity of the lactoperoxidase system: a review. Journal of Food Protection, v. 56, n. 10, p. 887-892, out.1993. 